\title{
THE DEVELOPMENT AND INDUSTRIALIZATION RECOMMENDATION OF CURRENT AERIAL REMOTE SENSING TECHNOLOGY
}

\author{
Zhigang HONG
}

Chinese Academy of Surveying and Mapping ,Beijing 100830,China hongzg@casm.ac.cn

KEY WORDS: Aerial remote sensing industry, Industry expanding; Market competition Proceedings

\begin{abstract}
:
At present, the research development and industrialization of aerial remote sensing technology in China are faced with enormous requirements and developing chance. It is the strategic selection for remote sensing technology to perfect the construction of remote sensing technology system, implement the three strategies of science and technology development, standardize and improve the producing ability of remote sensing products, and make the remote sensing technology become a kind of industries. Based on industry economics principle and the characteristics of aerial remote sensing technology, this paper put forward the suggestions on technological development, industrialization, and market competition of aerial remote sensing industrialization.
\end{abstract}

\section{INTRODUCTION}

Remote sensing is a technology that the use of satellites, manned aircraft, unmanned aircraft, airships, and other aerospace vehicle, carrying various types of imaging sensors for electromagnetic signals radiated by the Earth's surface of the natural and cultural landscape to extract natural and cultural information by image processing. It plays a vital role in many aspects, such as basic surveying and mapping, land and resources management, forestry resources and ecological environment survey, natural disaster monitoring and military reconnaissance.

Satellite space remote sensing systems, aviation (in the highaltitude, near-Earth space) remote sensing systems as important parts of the earth observation system, both have their own characteristics, complementary. Among which, Aerial remote sensing with autonomy, high precision, high efficiency, flexible and convenient become effective means to access to highprecision remote sensing data. To this end, mapping departments actively promote technological innovation and transformation, and vigorously promote the aerial remote sensing system to improve remote sensing data acquisition, processing and application capabilities, and promote the development of the remote sensing industry.

\section{THE FOREIGN DEVELOPMENT SITUATION OF AVIATION REMOTE SENSING}

With the development of a series of technologies include modern aircraft, sensor, and image processing software, aerial remote sensing system shows coordinated development of military, public welfare, and commercialization and trend with high-precision, light and small, integrated applications and industrial.
2.1 Coordinated development of military, public welfare and commercialization.

An advanced and complete remote sensing earth observation system should be consisted of military, welfare, and commercial remote sensing. In order to safeguard national sovereignty, protect national security, military remote sensing represents the country's highest technical level; welfare remote sensing works to improve the space for earth observation and cognitive abilities, develop and improve the scientific level of the earth sciences and earth system, protect the ecological environment and enhanced capacity to respond to natural disasters; commercial remote sensing pursues business profits by means of improving the resolution of the remote sensing data and the ability to obtain the data, using information and added value of data and information, has become an important part of geomatics industry.

\subsection{Light and small, high-precision, integrated applications.}

As low cost and flexibility of Small light aircraft, light and small flying platform gradually become a main flight of Remote Sensing; at same time, in order to meet the requirements of small light aircraft platform load, the aviation digital cameras and airborne LiDAR sensor has gradually become digitization and miniaturization; in addition, The integrated application of high-precision positioning and orientation system and inertial stable platform improved the accuracy and efficiency of aerial remote sensing.

\subsection{Business and industrial development.}

Enterprises as the mainstay, work to promote the industrialization of Earth observation, aerial remote sensing applications range from the original main auxiliary of the government's macro decision-making, to various fields like economic construction and social development; emphasis on multi-source image fusion among high spatial resolution, high spectral resolution and high time resolution images, information processing and services, has formed a more complete remote 
sensing information industry chain; rapid rise in operating airborne remote sensing technology and its data supply companies in the United States and Europe, marked the commercialization and industrialization of aerial remote sensing, especially much develop under the support of government and military of these countries.

\section{DEVELOPMENT STATUS OF DOMESTIC AVIATION REMOTE SENSING}

The domestic aviation remote sensing technology, starting from the 1970s, after ten years of hard work, has developed into the practical. Overviews of China's aviation remote sensing industry, has experienced three developmental periods, as shown in Figure 1.

\subsection{Introduced and popularized the concept period.}

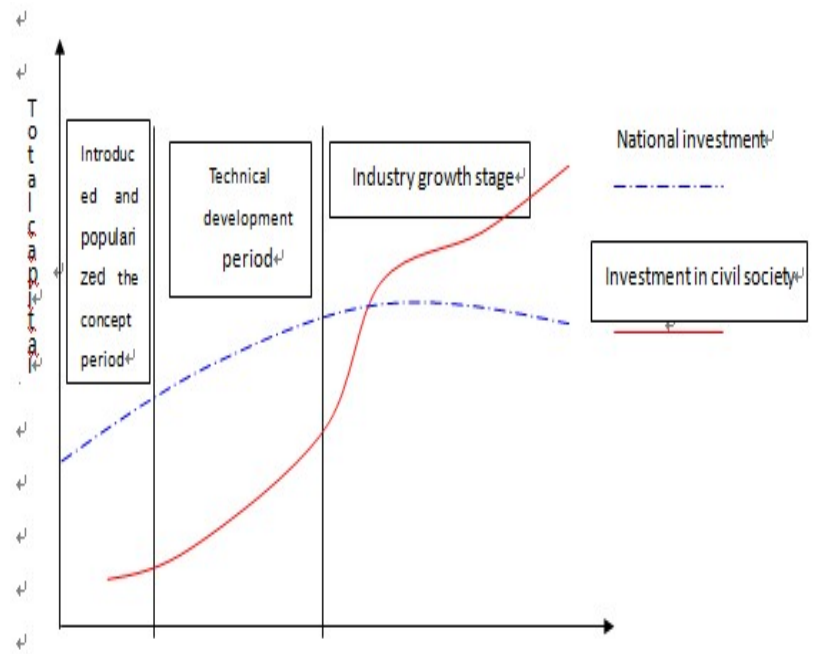

Remote Sensing basic theory, method and application test were promoted.

\subsection{Technology growth stage.}

With the development of remote sensing science and technology, the field of aerial remote sensing applications has been gradually expanded. Since the founding of state, the government invests a large-scale resource to environmental Investigation, because of the limit of earth observation technology and equipment, professional teams used aerial remote sensing means, accorded to uniform specifications and technology acquisition, processed and centralized storage, besides, information service agencies were responsible for the distribution and management of information.

\subsection{Industrial growth stage.}

Aerial remote sensing industry gradually developed with the process from nonexistence to existence and from small to large. National investment gradually increased with the development of remote sensing applications, especially in infrastructure construction. With the increase in national investment, the remote sensing market open further to increase the confidence in private capital, began to increase input; invest in the country reaches a certain climax, the exponential growth of private capital into the field changes aerospace remote sensing capital structure, private capital will reach more than the national investment, in the same time, state capital in the field of aerospace remote sensing will gradually reduce when the private capital market development further enhance and aerial remote sensing industry market capacity further increase. At present, China's aviation remote sensing industry is in a period of development of the third generation.

\section{CHALLENGES FACING THE DEVELOPMENT OF THE DOMESTIC AVIATION REMOTE SENSING}

Domestic aviation remote sensing has a long history and develops rapidly. More and more enterprises engaged in aerial remote sensing and aerial photography. Aerial remote sensing has become a better part of our field of geospatial information industry. However, due to the overall planning of the development of the domestic aviation remote sensing to coordinate management and market supervision is relatively weak, mechanisms for the sharing of information resources between sectors and regions has not yet been established. The low level of remote sensing information access and resource development and utilization of key technology capability of independent innovation, remote sensing applications, business and industrialization are existent problems. Mainly in:

\subsection{Lack of top-level design and co-ordination.}

A long time, water conservancy, mining, land, agriculture and other departments actively developed aerial remote sensing system to serve the industry, different departmentalized repeated acquisition and processing of images of the same area is also very prominent phenomenon. Remote sensing image processing standard of the departments are not unified, the lack of copyright protection and information sharing coordination mechanism, resulting in outcomes of single-use and sharing of information is difficult; airspace management system is not perfect, and remote sensing images confidentiality regulatory, resulting in the procedure of the declaration and approval of the flight plan is complexity, to some extent, restricted the application of aerial remote sensing system.

\subsection{Lack of innovative spirit and ability.}

Domestic aviation remote sensing field could not basically get rid of the development model of tracking and imitate. The development and manufacture of aerial remote sensing system tend to attach importance to the integration technology, ignore the basic technology, neglect professional flying platform, highprecision positioning and orientation system with stable platform, independent intellectual property rights measurement type camera and software system to adapt to light small airborne remote sensing. A lot of the core critical components and parts still rely on foreign procurement that blocked from abroad. This situation seriously restricts the development of China's aviation remote sensing technology.

4.3 Small, scattered, chaotic phenomena exist on the industry as a whole.

As the absence of the dominant ideology of the overall strategic research and industrial development, the domestic aviation remote sensing industry has the spontaneity and blindness. SMEs aerial remote sensing was the industry body. Nearly a thousand of firms were specialized in aerial remote sensing trade, small market size disorderly and vicious competition is brutal. As technology research and industrial development out of line, no more conscious of the technical division of labor and the main direction has formed. Because of the size and economic strength is relatively weak, investment is not strong 
enough to affect the speed of technological development, lead to the industry lack of core competitiveness.

\section{PROPOSAL}

Based on new principles of earth observation, by the concept innovation, technology innovation, management innovation, institutional innovation, optimization of the development environment and perfect protection measures, promote China's aviation remote sensing technology and industrial development.

\subsection{Strengthen top-level design, overall planning, coordinated} development.

Deal with the structure of country's earth observation system. Strengthen civil-military integration, better deal with the mutually independent but interrelated and coordinated development relationship among the military, public welfare, and the commercialization of remote sensing systems. Strengthen policy research, open the investment in aerial remote sensing, promote the sharing and open of geographic information data, reasonably adjust the data privacy policy, establish a classification system and supplemented by technical means, and this can both to ensure the state secrets, but also to achieve the sharing and application extensions. Consummate service system, and to proceed to resolve issues such as airspace management, further simplify the program of airspace coordination.

5.2 Increase the development and promotion of highprecision, light and small aerial remote sensing system; promote to modular, standardized, diversification and serialization development.

With the traction of demand, combine user, production, school, research and management as a way to encourage scientific research institutions and enterprises to develop their own intellectual property rights product development, realize Surveying, Mapping and Remote Sensing, dedicated longendurance aircraft, multi-lens digital camera of big frame image, high-precision positioning and directional control system (DGPS / IMU) integrated, break through the limit of core technology in aerial remote sensing observation performance and the ability of data processing applications to improve system reliability and stability; integrating the armed forces, to speed up the conversion of military technology into civilian using, to optimize aerial remote sensing technology equipment and infrastructure rational distribution.

\subsection{Promote the balanced development of the remote sensing} information industry chain.

In the event that a large number of inputs put into satellite remote sensing and aerial remote sensing undertaking, market tilt toward domestic enterprises, in accordance with the military and civilian officials to help to support enterprise with data and information procurement, service outsourcing development to train, and support a number of promising enterprises; guide and encourage the integration and reorganization of enterprises, as well as a combination with capital market; around strategic spatial information industry development, bring into being industry chain including aircraft, light sensors, data processing software, aerial photography flight, data generation processing, data application development and technical services; from the point of view of the development of the industry, put industry self-regulation into practice, promote cartel symbiotic, realize China's remote sensing industry prosperously.

\section{References}

[1]Zhao Yingshi,Principles and methods of remote sensing application analysis.Social Sciences Academic Press, Beijing.

[2]Xu Deming,China Surveying and Mapping Development Report (2010) .Social Sciences Academic Press, Beijing.

[3] 2009 Statistical Bulletin of Surveying and Mapping.State Bureau of Surveying and Mapping Management Information Center ,Beijing.

[4]Gan Yanling,Liu Xianlin,Duan Fuzhou,2011High-precision light small airborne remote sensing systems integration technologies and methods.Scienceof Surveying and Mapping,36(1),pp.84-87.

[5] National Remote Sensing Centre Annual Report 2010. National Remote Sensing Center.

[6]Jing Guifei,2007,Current remote sensing technology development and industrialization of analysis.Geographic Information World,3pp,6-15.

[7] U.S. National Institute of Earth Science, Environment and Natural Resources Committee: Earth Sciences and Resources Bureau rediscovered Committee.Rediscovered geography. Academy Press ,Beijing.

[8]Wang Xiaohai,2004,The development of the modern remote sensing satellite applications and commercialization.China Aerospace, 2pp,17-23.

\section{Acknowledgements}

Funding for this paper was provided by National Natural Science Foundation of China 41271451 and The Key Laboratory of Mapping from Space, National Administration of Surveying, Mapping and Geoinformation K201201. 